\title{
Intravenous Leiomyomatosis
}

National Cancer Institute

\section{Source}

National Cancer Institute. Intravenous Leiomyomatosis. NCI Thesaurus. Code C4518.

A rare benign neoplasm characterized by the presence of smooth muscle cells growing within veins. 